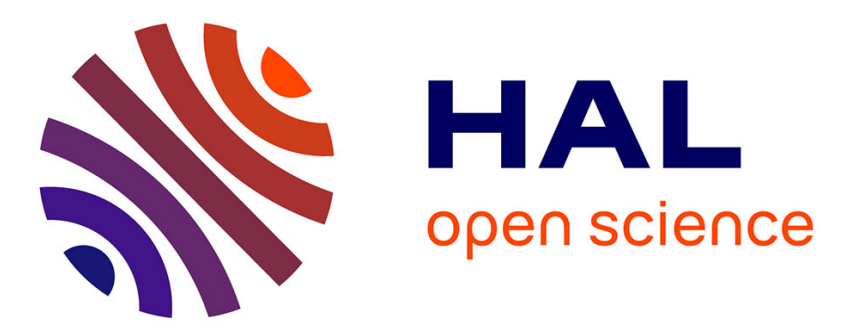

\title{
Easy-to-Use Osmosis-Based Microfluidic Chip for Protein Crystallization: Application to a Monoclonal Antibody
}

Sandy Morais, Gérald Clisson, Teresa Fina Mastropietro, Maria L Briuglia, Joop H ter Horst, Jacques Leng, Jean-Baptiste Salmon

\section{To cite this version:}

Sandy Morais, Gérald Clisson, Teresa Fina Mastropietro, Maria L Briuglia, Joop H ter Horst, et al.. Easy-to-Use Osmosis-Based Microfluidic Chip for Protein Crystallization: Application to a Monoclonal Antibody. Crystal Growth \& Design, In press, 10.1021/acs.cgd.1c00248 . hal-03215559

\author{
HAL Id: hal-03215559 \\ https://hal.science/hal-03215559
}

Submitted on 3 May 2021

HAL is a multi-disciplinary open access archive for the deposit and dissemination of scientific research documents, whether they are published or not. The documents may come from teaching and research institutions in France or abroad, or from public or private research centers.
L'archive ouverte pluridisciplinaire HAL, est destinée au dépôt et à la diffusion de documents scientifiques de niveau recherche, publiés ou non, émanant des établissements d'enseignement et de recherche français ou étrangers, des laboratoires publics ou privés. 


\title{
An easy to use osmosis-based microfluidic chip for protein crystallization: application to a monoclonal antibody
}

\author{
Sandy Morais, ${ }^{\dagger}$ Gérald Clisson, ${ }^{\dagger}$ Teresa Fina Mastropietro, ${ }^{\ddagger}$ Maria L. Briuglia, $\mathbb{1}$ \\ Joop H. ter Horst, ${ }^{\mathbb{I}}$ Jacques Leng, ${ }^{\S}$ and Jean-Baptiste Salmon ${ }^{*} \S$ \\ †CNRS, Solvay, LOF, UMR 5258, Université de Bordeaux, F-33600 Pessac, France. \\ $\ddagger$ Istituto per la Tecnologia delle Membrane, CNR, Via P. Bucci Cubo 17C, Rende 87036, \\ Italy \\ IEPSRC Centre for Innovative Manufacturing in Continuous Manufacturing and \\ Crystallisation, Strathclyde Institute of Pharmacy and Biomedical Sciences, University of \\ Strathclyde, 99 George Street, Glasgow, G1 1RD, UK \\ UFR des Sciences et Techniques, Laboratoire SMS-EA3233, Université de Rouen \\ Normandie, Place Emile Blondel, Mont-Saint-Aignan 76821, France \\ $\S C N R S$, Solvay, LOF, UMR 5258, Univ. Bordeaux, F-33600 Pessac, France. \\ E-mail: jean-baptiste.salmon-exterieur@solvay.com
}

\section{Abstract}

We developed a disposable microfluidic chip which mimics the vapor diffusion method for exploring protein crystallization conditions, but at the nanoliter scale. This device exploits the permeation of water through a thin poly(dimethylsiloxane) (PDMS) layer separating droplets stored in the chip and containing a mixture of proteins and precipitants, from an open microfluidic reservoir. The water chemical activity fixed by the reservoir makes it possible to modify the volume of the droplets in a controlled way (reduction or increase). Since PDMS is only permeable to water, the imposed water activity therefore increases or decreases the concentration of the solutes present in the droplet, and thus consequently the supersaturation of the solution. The specificity of our approach, in addition to the low volumes ensuring controlled mass transport conditions, is that the concentration of all the solutes is known at any time, thus allowing extraction of quantitative information on the crystallization process. We exploit these chips on a protein of therapeutic interest: the full-length monoclonal antibody anti-CD20. Our experiments allow us in particular to estimate both the solubility of this protein and the width of the metastable zone with $\mathrm{Na}_{2} \mathrm{SO}_{4}$ and PEG400 as crystallizing agents. We also show that the fine tuning of the permeation rate makes it possible to perform crystallization/dissolution cycles to selectively dissolve small crystals and increase the mean size of the remaining anti-CD20 crystals.

\section{Introduction}

Protein crystallization is not only one of the techniques of choice to reveal their 3D structures by X-ray diffraction, and thus understand their biological function, but also a possible method of purification and production of drugs for the pharmaceutical industry. ${ }^{1}$ However, finding the optimal conditions for crystallizing a given protein is a particularly arduous task. Indeed, it requires numerous trials 
to explore a wide range of parameters (precipitants, $\mathrm{pH}$, concentrations, etc.), while finely controlling the kinetics of the crystallization. ${ }^{2-5}$ Among the many existing techniques, the hanging (or sitting) drop vapor diffusion method is the simplest to achieve such a task. This technique consists of depositing a drop of a few microliters containing a mixture of proteins and reagents close to a reservoir containing a higher concentration of reagents. The balancing of the water chemical activities between the drop and the reservoir, by "vapor diffusion", then allows the slow increase of the supersaturation in the drop, and possibly the appearance of crystals. Once a hit of crystallization has been found, fine tuning around the crystallization conditions is generally performed notably to produce crystals suitable for X-ray analysis.

Since the advent of microfluidics in the 1990s, many groups have developed innovative chips for screening protein crystallization and optimizing crystal growth once hits are found. ${ }^{6-12}$ The advantages of microfluidics do not only lie in the ability to handle minute amounts of samples (a major asset for proteins that are difficult to produce and purify), but also in the control of transport phenomena allowing fine exploration of the crystallization conditions, and in particular the kinetics. Among these microfluidic developments, we can notably mention batch crystallization in closed microchannels or droplets of a few nanoliters, ${ }^{13-22}$ controlled interdiffusion of proteins and precipitants, ${ }^{23-26}$ or chips integrating membranes to mimic dialysis crystallization. ${ }^{27,28}$ Beyond the screening of crystallization conditions for structural analysis (sometimes in situ), some of these devices have also been developed for the acquisition of data difficult to measure on a macroscopic scale (phase diagram and solubility, ${ }^{14,22,23} \mathrm{nu}$ cleation kinetics, ${ }^{18-20}$ protein-protein interactions, ${ }^{29}$ etc.).

Among the works cited above, some exploit osmosis to reproduce the vapor diffusion method at the microfluidic scale. ${ }^{30-32}$ More precisely, these tools make possible to increase the supersaturation of a solution confined in a microchannel, by the removal of water through a thin poly(dimethylsiloxane) (PDMS) layer sep- arating this solution from a reservoir imposing a given water chemical activity. As PDMS is not permeable to proteins, salts, and polymers, this technique mimics, in a way, the vapor diffusion technique, but also offers many advantages such as local observations using state-of-the-art microscopy, a dynamic control of the water permeation, and obviously high-throughput screening with samples of a few microliters. Nevertheless, these tools require dedicated equipments (pressure regulators, syringe pumps) and a strong expertise to ensure their operation (dropletbased microfluidics, valves, etc.).

Recently, we developed a microfluidic tool that exploits water pervaporation to explore the phase diagram of complex fluids. ${ }^{33}$ The principle of this chip consists in storing a linear drop of a few nanoliters and length $L$ of a few millimeters in a microchannel made of a thin layer of PDMS sealed with a glass slide. Pervaporation of water through PDMS towards the ambient air causes the drop volume to decrease, and therefore increases the concentration of the solutes contained in the drop. Strikingly, we have shown that solute concentration remains homogeneous in the drop whatever the solute and the length $L{ }^{33}$ This result is not due to molecular diffusion along the drop because the associated time scales are extremely long, but is in fact related to the homogeneous pervaporation that induces a flow. This unique feature along with the linear geometry of the drop allows to know quantitatively the composition of the drop at any time $t$, simply by measuring its length $L$ (and thus its volume) and using the solute conservation. In the past few years, we used this chip to measure quantitatively the phase diagram of multi-component aqueous solutions, ${ }^{33,34}$ see also Ref. ${ }^{35-37}$ for other works based on similar ideas.

The aim of the present work is to adapt this chip for protein crystallization experiments, and to illustrate its potential by performing crystallization experiments of a fulllength monoclonal antibody (mAb) of strong therapeutic interest: anti-cluster of differentiation 20, anti-CD20. ${ }^{38}$ In section Results, we first describe the operation of the microfluidic device, then we report crystallization and disso- 
lution experiments of anti-CD20 with $\mathrm{Na}_{2} \mathrm{SO}_{4}$ and PEG400 as crystallizing agents. Finally, an approach with repeated cycles of growth and dissolution is given.

\section{Materials and Methods}

\section{The two-level microfluidic device}

The design of the two-level microfluidic chip is shown in Fig. 1(a). The "crystallization level" (referred below to as level C) consists of 78 identical parallel dead-end channels of length $L_{0}=3.4 \mathrm{~mm}$ and width $w=90 \mu \mathrm{m}$. This set of channels makes a square of about $7 \times 8 \mathrm{~mm}^{2}$. This design makes it possible to store 78 identical droplets in the parallel channels, and thus to screen a given condition 78 times on a unique chip. Note that in this linear geometry, the volume $V$ of the droplets stored in the channels is related to their length $L$ according to $V \simeq(h w) L$. For a channel height $h=30 \mu \mathrm{m}$, the volume of each channel is $(h w) L_{0} \simeq 9 \mathrm{~nL}$. All the channels are connected to a common inlet (inlet $\mathrm{C}$ ) and outlet (outlet $\mathrm{C}$ ).

The "fluid reservoir level" referred below to as level $\mathrm{F}$ simply consists of a rectangular open reservoir of lateral dimensions $\simeq 8 \times 9 \mathrm{~mm}^{2}$, as shown in Fig. 1(b). The whole chip corresponds to the superimposition of levels $\mathrm{C}$ and $\mathrm{F}$, see Fig. 1(c).

\section{Microfabrication}

Our disposable two-level chips are made using multilayer soft lithography techniques. ${ }^{39}$ The master template of level $\mathrm{C}$ is made with a negative photoresist (SU-8 3025, MicroChem) on a 3 " silicon wafer. The height of the channels is $h=30 \mu \mathrm{m}$, and the use of 3 " wafers allows for the fabrication of 3 chips simultaneously. A thin layer of PDMS with its curing agent (Sylgard 184) is then spin-coated (1200 rpm for $40 \mathrm{~s}$ for a thickness $e=50 \mu \mathrm{m}$ ) on the mold and cured $1 \mathrm{~h}$ at $60^{\circ} \mathrm{C}$. Simultaneously, a thicker PDMS layer $(\simeq 7-10 \mathrm{~mm})$ is poured on a bare wafer and cured $1 \mathrm{~h}$. A rectangular area of dimensions $\simeq 8 \times 9 \mathrm{~mm}^{2}$ is then cut out of this layer to create the reservoir corresponding

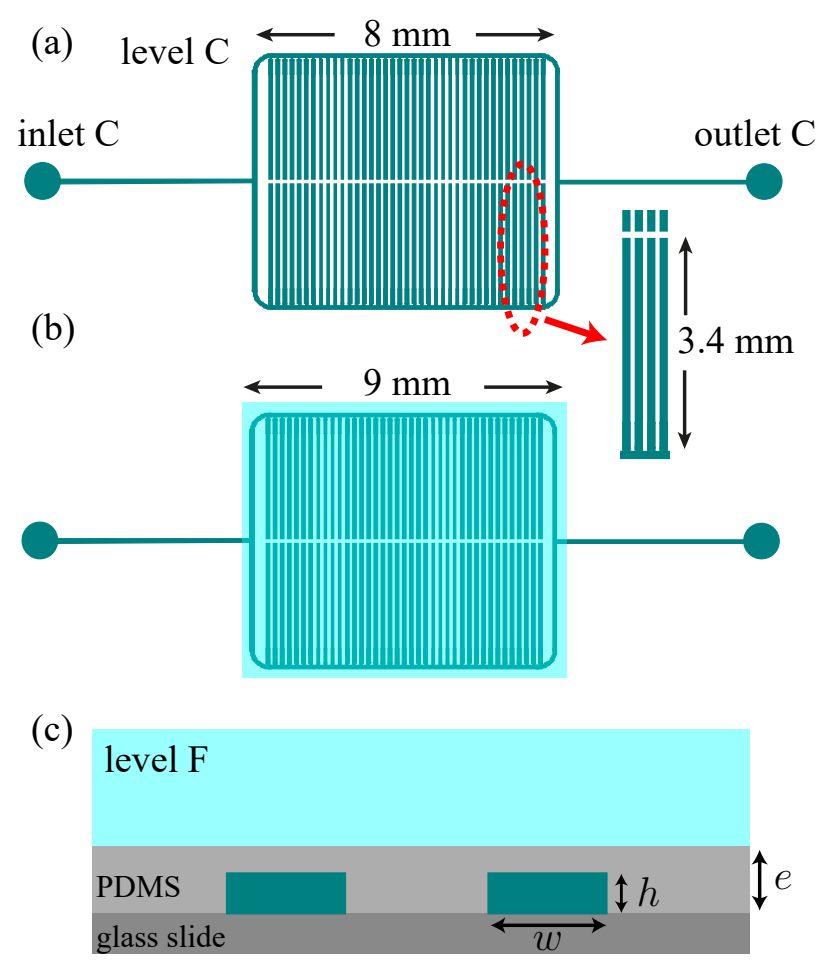

Figure 1: (a) Top view of level C, and (b) of the alignment of level $\mathrm{F}$ with level C. (c) Crosssection view showing the architecture of the two-level microfluidic chip.

to level F, and the PDMS layer is bonded to level $\mathrm{C}$ using a plasma activation. The whole PDMS structure is then carefully peeled off, punched for the fluid connections, and sealed with a glass slide using a plasma activation, see Fig. 1(c) for a cross-section view. Thanks to the plasma treatment, it is possible to operate the chip up to $\simeq 1$ bar without any leakage. The dimensions of the two-level chip are about $3 \times 1 \mathrm{~cm}^{2}$.

\section{Image acquisition and image anal- ysis}

The observation of the crystallization events is done using standard bright-field transmission microscopy. Our automated microscope (IX83 Olympus) coupled with a sCMOS camera (Orca Flash 4.0 Hamamatsu) and a motorized stage makes it possible to follow the crystallization at a high resolution, typically $0.3 \mu \mathrm{m} /$ pixel using a magnification of $20 \mathrm{X}$, and on a wide field of view. 
Custom-made image analysis programs (Matlab) were developed to estimate the lengths $L$ of the droplets as a function of time, as well as to estimate the density of crystals and their growth rate.

\section{Anti-CD20 mAbs solutions}

The crystallization experiments have been performed with aqueous solutions of anti-CD20 mAbs $\left(M_{w}=144.5 \mathrm{kDa}\right)$ provided by Fujifilm Diosynth Biotechnologies (Billiangham, UK). Sample vials are first thawed at room temperature during a couple of hours. Anti-CD20 concentration was measured using $\mathrm{UV} / \mathrm{Vis}$ absorbance at $280 \mathrm{~nm}$ (extinction coefficient $237380\left(\mathrm{M} \mathrm{cm}^{-1}\right)$. The initial concentration in the vials is about $9.9 \mathrm{mg} / \mathrm{mL}$ in a $25 \mathrm{mM}$ sodium citrate buffer at $\mathrm{pH}=6.5$. A buffer exchange is then operated on the mAbs samples. The volume of 5 aliquots are put in 2 centrifugal filter units (Amicon Ultra-15, cellulose membrane MWCO 10KDa, $4 \mathrm{~mL}$ per centrifugal filter unit). The solutions are then centrifuged at $8050 \mathrm{rpm}$ for $20 \mathrm{~min}$. Then, $2.5 \mathrm{~mL}$ of a solution of HEPES $100 \mathrm{mM}$ ( $\mathrm{pH}=7.7$ adjusted by $\mathrm{NaOH}$ ) is added to the remaining solution for buffer exchange. The solution is once again centrifuged at $8050 \mathrm{rpm}$ for $20 \mathrm{~min}$. The operation is repeated 3 times until the final volume reaches $1 \mathrm{~mL}$. The mAbs concentration in the final solution is $44.2 \mathrm{mg} / \mathrm{mL}$.

\section{Other chemicals}

Crystallizing agents for the mAbs solutions are PEG400 and $\mathrm{Na}_{2} \mathrm{SO}_{4}$ in a HEPES buffer (Sigma Aldrich). Fluorinert oil FC40 (3M) is used as an inert oil to store the droplets in the chip. Several aqueous $\mathrm{MgCl}_{2}$ solutions (Sigma Aldrich) were also prepared to tune the permeation rate though the PDMS. The water chemical activity $a_{w}^{i}$ of the $\mathrm{MgCl}_{2}$ solutions at different concentrations have already been reported in the literature. $^{40-42}$ In the following, we mainly discuss experiments performed at two different concentrations: $\left[\mathrm{MgCl}_{2}\right]=10 \mathrm{wt} \%$ leading to $a_{w}^{i} \simeq 0.93$, and $\left[\mathrm{MgCl}_{2}\right]=5 \mathrm{wt} \%$ leading to $a_{w}^{i} \simeq 0.97$ at room temperature (the water ac- tivity of electrolyte solutions weakly depends on the temperature). All chemicals were used as received without any purification steps.

\section{Operating protocol for a crystal- lization experiment}
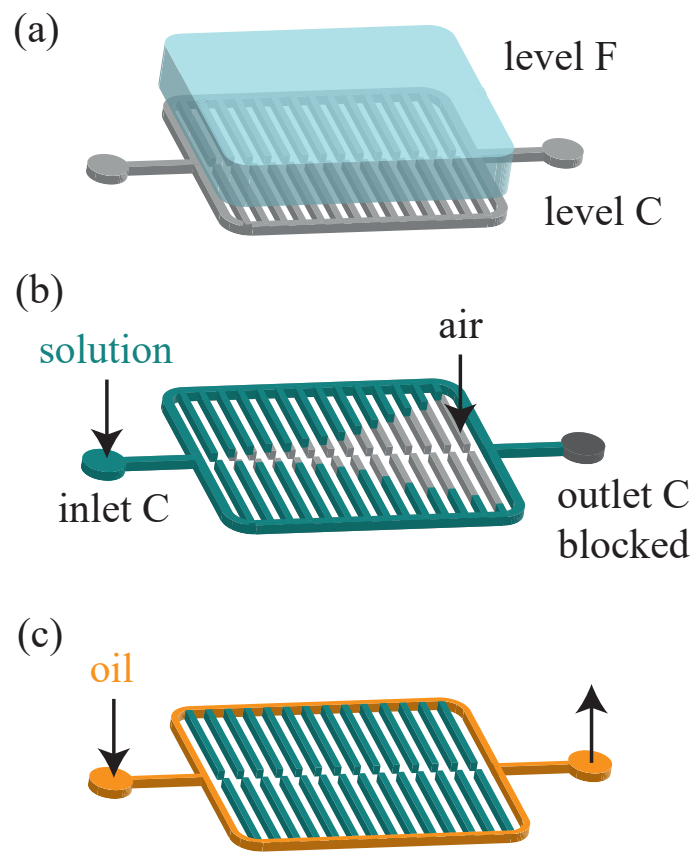

Figure 2: Protocol for a protein crystallization experiment: (a) filling of level $\mathrm{F}$ with a solution imposing a given water chemical activity; (b) filling of level $\mathrm{C}$ with the protein + precipitants solution (outlet $\mathrm{C}$ is closed); (c) flow of oil from inlet $\mathrm{C}$ to outlet $\mathrm{C}$ to store the droplets.

Figure 2 shows schematically the protocol for using the two-level chip for a protein crystallization experiment. A volume of $\simeq 100-300 \mu \mathrm{L}$ of a given aqueous solution is pipetted in the reservoir of level $\mathrm{F}$ of the chip, see Fig. 2(a). Level $\mathrm{C}$ is then gently filled manually with a crystallization mixture (protein + precipitants) using a syringe through inlet $\mathrm{C}$, while outlet $\mathrm{C}$ is closed with a dead-end tube, see Fig. 2(b). The consumption of solution is about $1 \mu \mathrm{L}$ to fill the whole network of channels, even if larger volumes are required to fill the tubes (typically $50 \mu \mathrm{L}$, but the remaining solution can be reused). The filling of the dead-end channels is possible because the entrapped gas slowly permeates through the thin PDMS layer. 
Then, outlet $\mathrm{C}$ is opened again, and a flow of fluorinated oil is imposed manually from inlet $\mathrm{C}$ to outlet $\mathrm{C}$ using a syringe. This flow enables the formation and the trapping of 78 identical droplets in the parallel chambers, see Fig. 2(c). In order to limit the evaporation of the water contained in level $\mathrm{F}$, a thin glass slide is finally placed on top of the chip to close the open reservoir.

Note that all these steps do not require the use of syringe pumps or pressure controllers, and last typically a few minutes.

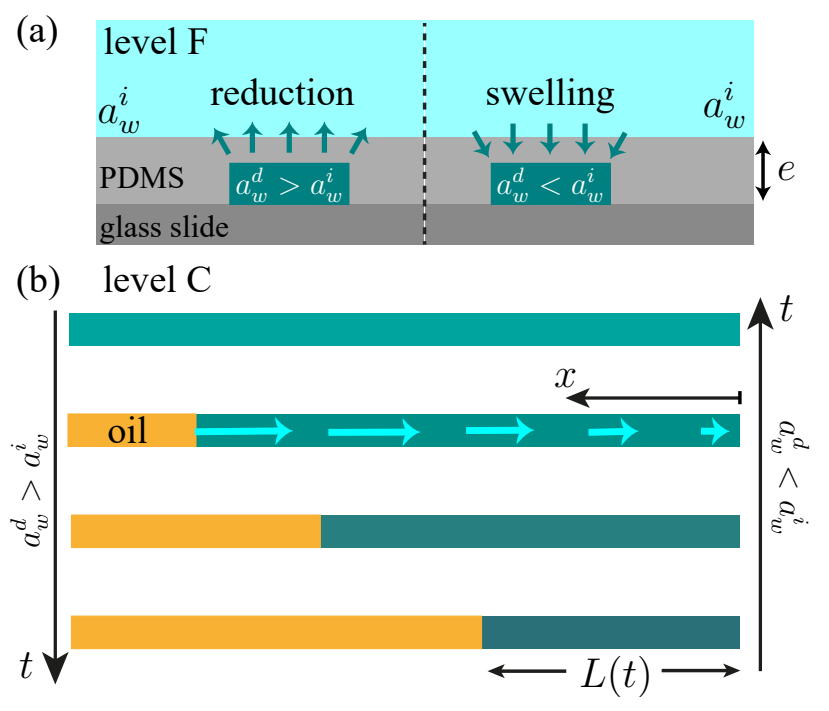

Figure 3: (a) Cross-section view, arrows show the water flux to balance the water chemical activities between levels $\mathrm{C}$ and $\mathrm{F}$, increasing the concentrations in the drop $\left(a_{w}^{d}>a_{w}^{i}\right)$ or diluting the drop $\left(a_{w}^{d}<a_{w}^{i}\right)$. (b) Top view evidencing the reduction or the increase of the drop length, the color scale indicates the solute concentration. The arrows show the permeation-induced flow $v(x)$ in the drop in the case $a_{w}^{d}>a_{w}^{i}$ at a given instant.

\section{Results}

\section{Functioning of the chip}

The two-level PDMS chip shown schematically in Fig. 3 can be used to reproduce the vapor diffusion method for protein crystallization at a nanoliter scale.
Indeed, droplets containing proteins and precipitants can be stored in level $\mathrm{C}$, while a fixed chemical activity $a_{w}^{i}$ is imposed by the solution in level $\mathrm{F}$, for instance a concentrated precipitant solution or a salty aqueous solution. Water therefore permeates through the PDMS layer to balance the water chemical activity of the droplets stored in level $\mathrm{C}$ with that imposed in level $\mathrm{F}$, as the transport by vapor diffusion in the hanging (or sitting) drop method. This water flux tends to reduce (or increase) the length of the droplets contained in level $\mathrm{C}$ in order to increase (or decrease) solute concentrations up to balancing the water chemical activity difference, see Fig. 3.

Importantly, water permeation along the channels translates into a flow within the droplets due to mass conservation, see Fig. 3(b), and given by:

$$
v(x)=-\frac{q_{e}\left(a_{w}^{d}-a_{w}^{i}\right)}{h w} x,
$$

where $a_{w}^{d}$ is the water chemical activity in the droplets (depending on their content), $a_{w}^{i}$ the water chemical activity in level $\mathrm{F}$, and $q_{e}$ a linear permeation rate $\left(\mathrm{m}^{2} / \mathrm{s}\right)$ depending on the geometry of the chip. ${ }^{43-45}$ This permeationinduced flow makes it possible to estimate the dynamics of the droplets $L$ vs. $t$ but also indicates that the local shrinkage/swelling rate of an elementary volume $V$ of the drop is given by

$$
d V=\frac{\partial v(x)}{\partial x} V=-\frac{q_{e}\left(a_{w}^{d}-a_{w}^{i}\right)}{h w} V
$$

When diffusion ensures that the concentration of the solutes contained in the droplets is homogeneous across the channel cross-sections $(h \times$ $w)$, the local shrinkage/swelling rate is homogeneous along the droplets, and solutes get concentrated/diluted homogeneously, whatever the length of the droplets, see Ref. ${ }^{33}$ for a detailed demonstration of this result including its range of validity. The composition of the drops at any instant is therefore known simply by measuring the length of the drops and using the solute conservation:

$$
L(t) C(t)=L_{0} C_{0}
$$


where $C$ is the concentration of a given solute, $C_{0}$ its initial concentration, and $L_{0}=L(t=0)$ the initial length of the drop.

In the design shown in Fig. 1 corresponding to storage parallel channels separated by a distance $110 \mu \mathrm{m}$, the linear permeation rate in Eq. (1) can be estimated by the 1D diffusive flux through the PDMS layer: ${ }^{43-45}$

$$
q_{e} \simeq w \frac{D_{s} \nu_{s} c_{s}}{e-h} \simeq 2.8 \times 10^{-12} \mathrm{~m}^{2} / \mathrm{s}
$$

where $D_{s} \simeq 8.5 \times 10^{-10} \mathrm{~m}^{2} / \mathrm{s}$ is the diffusivity of water in PDMS, $c_{s} \simeq 40 \mathrm{~mol} / \mathrm{m}^{3}$ the water concentration in PDMS at saturation, and $\nu_{s} \simeq 1.805 \times 10^{-5} \mathrm{~m}^{3} / \mathrm{mol}$ the molar volume of water. As $D_{s}$ and $c_{s}$ only slightly depend on temperature, ${ }^{46}$ the linear permeation rate will not show significant fluctuations with temperature. This crude estimate makes it possible to know the dynamics of equilibration of the droplets using Eq. (1) at $x=L$. In the experiments reported below, the small initial difference of water chemical activity (typically $\left.\left(a_{w}^{d}-a_{w}^{i}\right) \leq 0.05\right)$ associated to the time scales $(h w) / q_{e} \simeq 15 \mathrm{~min}$, leads to equilibration times of the order of the day. Note that the overall water permeation rate through the PDMS layer never exceeds $78 L_{0} q_{e}\left(a_{w}^{d}-a_{w}^{i}\right) \simeq 0.1 \mu \mathrm{L} / \mathrm{h}$ estimated with $L_{0}=3.4 \mathrm{~mm}$ for the design shown in Fig. 1 and for $a_{w}^{d}-a_{w}^{i}=0.05$. This small value compared to the volume of level $\mathrm{F}, \simeq 100$ $300 \mu \mathrm{L}$, ensures that level $\mathrm{F}$ indeed plays the role of a reservoir imposing a fixed water chemical activity $a_{w}^{i}$ to the droplets stored in level C.

\section{mAbs crystallization}

The crystallization solutions are made by mixing $500 \mu \mathrm{L}$ of the anti-CD20 solution (in HEPES $1 \mathrm{M} \mathrm{pH}=7.7$ ) prepared by the protocol described in Materials and Methods, and $500 \mu \mathrm{L}$ of a solution containing PEG400 at a volume fraction $9.6 \% \mathrm{v}$, and $\mathrm{Na}_{2} \mathrm{SO}_{4}$ at a concentration $0.85 \mathrm{M}$ in a HEPES buffer $(0.09 \mathrm{M}$, $\mathrm{pH}=7.4)$. These conditions of crystallization were reported recently using both vapor diffusion and meso-batch crystallization conditions. ${ }^{4-49}$ Droplets of this solution are stored in level $\mathrm{C}$ of the chip using the protocol described above. In level $\mathrm{F}$, we used a solution of $\mathrm{MgCl}_{2}$ at a concentration $\left[\mathrm{MgCl}_{2}\right]=10 \mathrm{wt} \%$. This concentration was chosen as its water chemical activity $a_{w}^{i}=0.93$ is slightly lower than the estimated water activity of the (non-diluted) solution of precipitants. ${ }^{50}$

The initial configuration of the experiment consists of 78 identical droplets of initial length $L_{0}=3.4 \mathrm{~mm}$ at the solute concentrations $C_{i}$ listed in Table 1. Due to the imbalance of water chemical activity, water permeates through the PDMS layer to reduce the drop volume and thus homogeneously concentrates the droplet solution. Figure 4(a) shows a channel at different times during the process, and Fig. 4(b) shows the corresponding path in the diagram [PEG400] vs. $\left[\mathrm{Na}_{2} \mathrm{SO}_{4}\right]$, see also Movie M1 in ESI corresponding to these data and showing simultaneously zooms on three distinct areas of the channel.

At $t \simeq 10 \mathrm{~h}$ [point $\mathrm{N}$ in Figure 4(b)], we observe the very first crystals in the channels with a minimal observable size $0.3 \mu \mathrm{m}$. At this time, the length of the droplets is $L \simeq 2500 \mu \mathrm{m}$ (ratio $L_{0} / L(t) \simeq 1.36$ ) leading to the concentrations in solutes listed in Table 1 using the solute conservation Eq. (3). For $t \simeq 11-15 \mathrm{~h}$, we observe an increase in the number of nucleating crystals and their growth until the longest ones display a well-defined needle-like shape with a length $\simeq 10 \mu \mathrm{m}$ along their main axis, see Fig. 4(a) for an image at $t=15 \mathrm{~h}$. These nucleation events are also accompanied by the appearance of turbidity, which could be the signature of a liquid-liquid phase separation as reported for the same system but with sitting-drop vapor diffusion and batch methods. ${ }^{49}$ The growth rate of these crystals is estimated from image analysis at about $\simeq 1-2 \mu \mathrm{m} / \mathrm{h}$ from $t \simeq 11 \mathrm{~h}$ to $15 \mathrm{~h}$. At later time scales, nucleation events are more rare and the existing crystals grow slowly at a rate $\simeq 0.5 \mu \mathrm{m} / \mathrm{h}$, until they reach an average length of about $12 \pm 5 \mu \mathrm{m}$ at $t \simeq 30 \mathrm{~h}$, see Fig. 4(a). For $t>30 \mathrm{~h}$, we no longer observe the growth of the crystals, and their density within the droplets (estimated from image analysis) is $\simeq 100 \pm 30$ crystals $/ \mathrm{nL}$ (the large error bar coming from the difficulty to identify crystals out of 


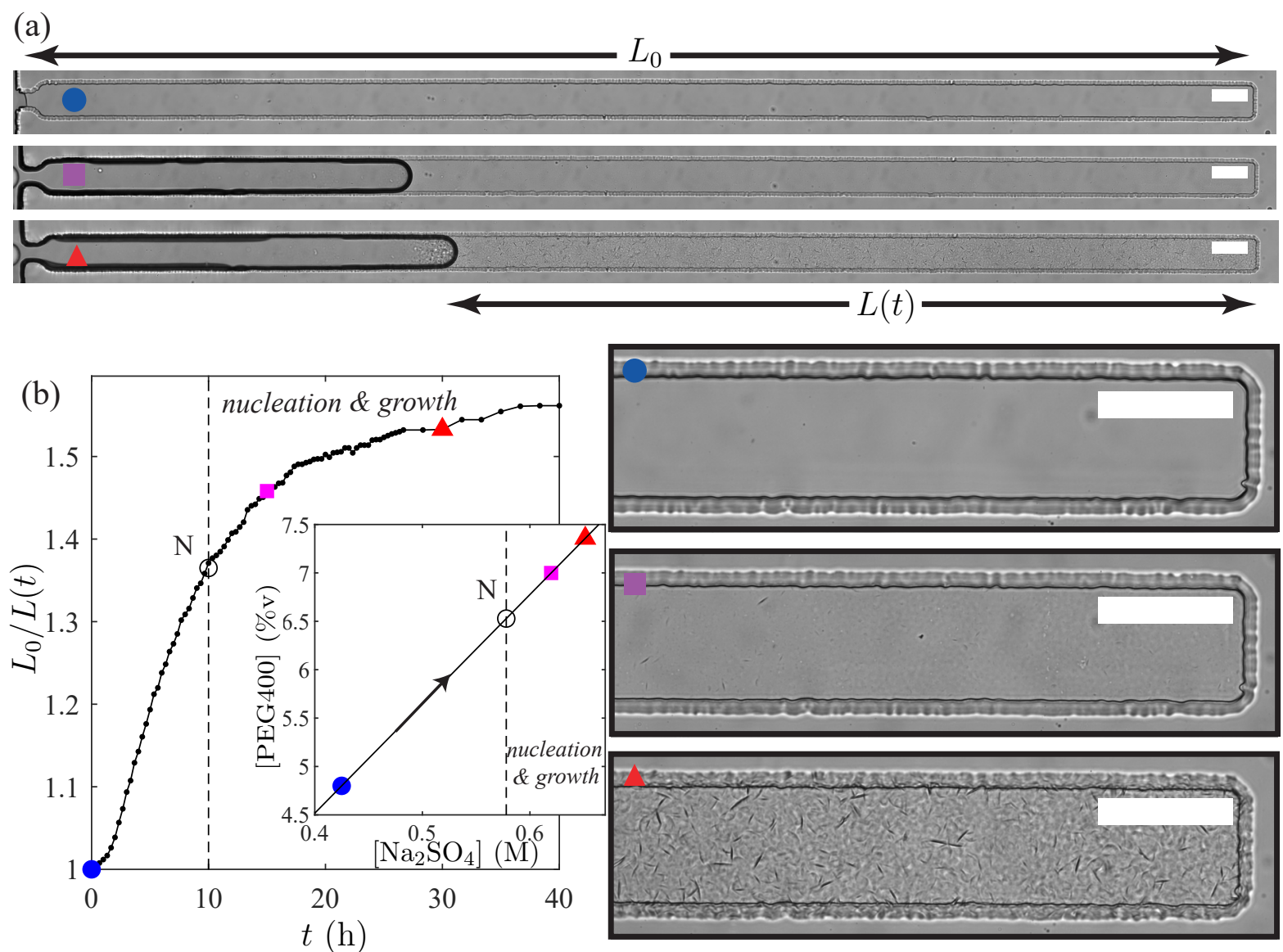

Figure 4: (a) Picture of one of the channels of level $\mathrm{C}$ at the beginning of the experiment $(\bullet)$, at $t=15 \mathrm{~h} \mathrm{(} \mathbf{\square})$, and $t=30 \mathrm{~h}(\mathbf{\Delta})$, see also the zooms at the end of the channel and Movie M1 in the ESI. In each image, the scale bar positioned in the protein solution droplet indicates $100 \mu \mathrm{m}$. (b) Evolution of the ratio $L_{0} / L(t)$ of a single droplet, the inset shows the kinetic path followed in the plane [PEG400] vs. $\left[\mathrm{Na}_{2} \mathrm{SO}_{4}\right]$. Point $\mathrm{N}$ indicates the appearance of the very first crystals. 
the focal plane). Importantly, all these observations are similar in the 78 stored droplets, and the very first crystals are observed when the droplets volume is $\simeq 6.7 \mathrm{~nL}$. The complete chemical equilibrium is reached after $\simeq 40 \mathrm{~h}$ as the droplets length reaches almost a constant value.

Table 1: Composition of the droplets stored in level $\mathrm{C}$ at different instants of the crystallization experiment reported in Fig. 4.

\begin{tabular}{|l|l|l|l|l|}
\hline point & $(\bullet)$ & $\mathrm{N}$ & $(\boldsymbol{口})$ & $(\mathbf{\Delta})$ \\
\hline \hline$t(\mathrm{~h})$ & 0 & 10 & 15 & 30 \\
{$\left[\mathrm{Na}_{2} \mathrm{SO}_{4}\right](\mathrm{M})$} & 0.425 & 0.58 & 0.62 & 0.65 \\
{$[\mathrm{PEG} 400](\% \mathrm{v})$} & 4.8 & 6.5 & 7.0 & 7.3 \\
{$[$ anti-CD20] $(\mathrm{mg} / \mathrm{mL})$} & 22.1 & 30.1 & $\mathrm{n} / \mathrm{a}$ & $\mathrm{n} / \mathrm{a}$ \\
\hline
\end{tabular}

\section{mAbs dissolution}

After the growth of the protein crystals in the experiment described above, we increased again the imposed water chemical activity $a_{w}^{i}$ by using distilled water in level $\mathrm{F}\left(a_{w}^{i}=1\right)$. This higher water activity now induces water transport from the reservoir of level $\mathrm{F}$ to the droplets of level C, see Eq. (1), therefore increasing the length of the droplets and possibly dissolving the crystals. Some pictures of this experiment are reported in Fig. 5 along with the kinetic path followed in the diagram [PEG400] vs. $\left[\mathrm{Na}_{2} \mathrm{SO}_{4}\right]$.

As for the crystallization experiment, the length of the droplets was used to estimate the concentrations in precipitants during the experiment using the solute conservation Eq. (3) (note that we implicitly neglect here the volume of the crystals). Dissolution of the crystals begins with the first disappearance of the smallest crystals only, see for instance the point $(\square)$ at a ratio $L_{0} / L \simeq 1.41$ leading to $[\mathrm{PEG} 400] \simeq$ $6.8 \% \mathrm{v}$ and $\left[\mathrm{Na}_{2} \mathrm{SO}_{4}\right] \simeq 0.6 \mathrm{M}$. Then, the bigger crystals fully dissolve when the ratio $L_{0} / L$ reaches $\simeq 1.34$ corresponding to the composition $[\mathrm{PEG} 400] \simeq 6.4 \% \mathrm{v},\left[\mathrm{Na}_{2} \mathrm{SO}_{4}\right] \simeq 0.57 \mathrm{M}$.

Strikingly, these data reveal that the complete dissolution of the crystals (at a protein concentration $C^{\star} \simeq 29.4 \mathrm{mg} / \mathrm{mL}$ ) almost coincides with the appearance of the very first (a)

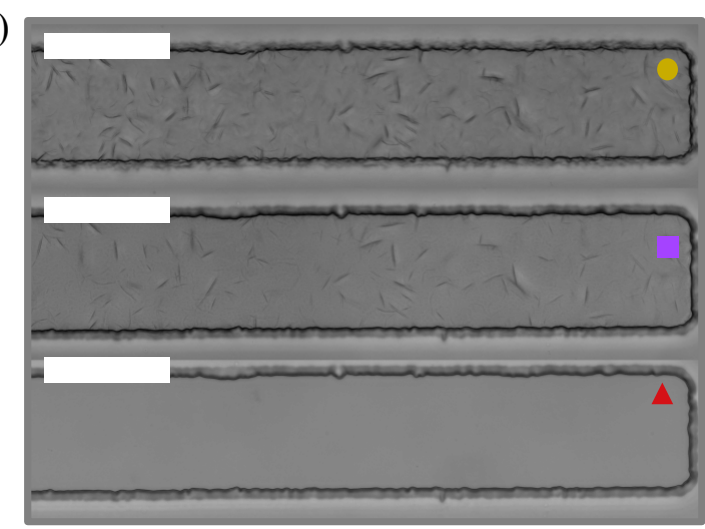

(b)

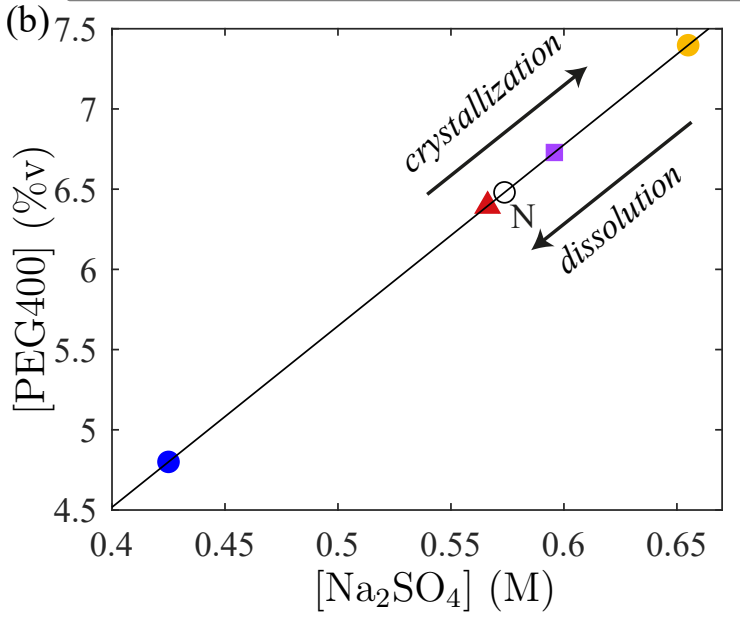

Figure 5: (a) Pictures of the tip of one channel at the points displayed in the diagram shown in (b), scale bar: $100 \mu \mathrm{m}$. In (b), the blue symbol $(\bullet)$ indicates the start point of the crystallization experiment and $(\bullet)$ the start point of the dissolution experiment. In ( $\square)$, only the smallest crystals have dissolved. The complete dissolution of all the crystals $(\boldsymbol{\Delta})$ almost coincides with point $\mathrm{N}(\mathrm{O})$ also shown in Fig. 4. 
crystals during the crystallization experiment [point $\mathrm{N}$ in Fig. 5(b), protein concentration $C_{N} \simeq 30.1 \mathrm{mg} / \mathrm{mL}$. This observation shows that the width of the metastable zone is narrow in our configuration, as we observe a small hysteresis between these two kinetic trajectories. This suggests that the crystallization of the mAbs is not limited by the nucleation step in the explored configuration but only by the slow growth of the crystals. Note also that these data give an idea of the prevailing supersaturation during nucleation, $S \simeq C_{N} / C^{\star}=1.02$, the exact supersaturation being not known as the precipitant concentrations are not strictly equal at point $\mathrm{N}$ and $(\mathbf{\Delta})$ in Fig. 5.

\section{Controlled growth of large crystals}

The observations reported above show the possibility to control the growth and the dissolution of the crystals, by fine tuning the solution in level F. We exploit this feature to grow large anti-CD20 mAbs crystals. Indeed, one can stop the dissolution process at point ( $\square)$ in the diagram shown in Fig. 5(b) to dissolve only the smallest crystals, and increase again the supersaturation by using a more concentrated $\mathrm{MgCl}_{2}$ solution in level $\mathrm{F}$. This step leads eventually to the re-growth of the existing crystals with a limited number of new nucleation events. By making several cycles of controlled dissolution/crystallization using two solutions of different water activity in level $\mathrm{F}\left(\left[\mathrm{MgCl}_{2}\right]=5\right.$ and $10 \mathrm{wt} \%$. leading to $a_{w}^{i} \simeq 0.97$ and $\simeq 0.93$ respectively), we managed to increase significantly the mean size of the anti-CD20 crystals from about $12 \pm 5 \mu \mathrm{m}$ for the initial crystallization step to $20 \pm 5 \mu \mathrm{m}$ after 3 cycles, see Fig. 6 . We chose a concentration of $\left[\mathrm{MgCl}_{2}\right]=5 \%$ instead of pure water in Level $\mathrm{F}$ in order to have a sufficiently low rate of increase of the droplet volumes, and thus slow dissolution of the crystals. Such a kinetic control of the crystallization process opens the possibility to obtain crystals with a sufficient size to determine their structure by X-ray diffraction measurements. Harvesting crystals from the chip would be possible if levels $\mathrm{C}$ and $\mathrm{F}$ were not irreversibly bound by plasma treatment, but external mechanical sup- port would be required in this case to prevent leakage during chip operation. Another possibility would be to replace the glass substrate in our multi-level chip with a material transparent to X-rays, and demonstrate that in situ collection of diffraction data is possible through the thin PDMS membrane.

(a)

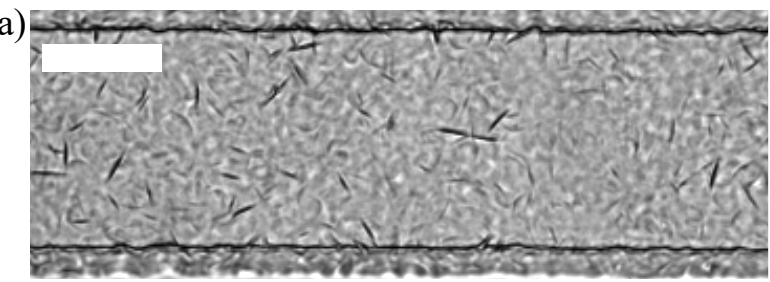

(b)

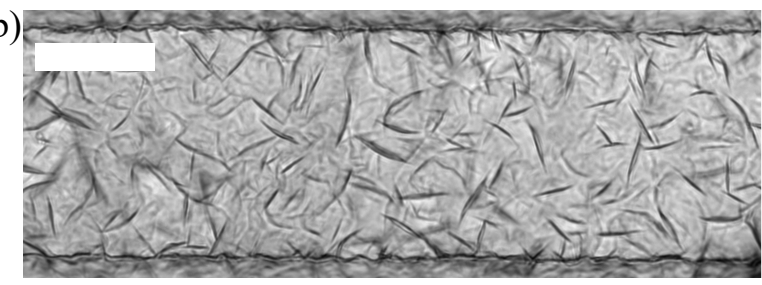

Figure 6: Picture of one of the channel of level C when chemical equilibrium is reached in the crystallization experiment, the size distribution of the crystals lies in the 1 to $10 \mu \mathrm{m}$ range. (b) Picture at equilibrium after 3 cycles of partial dissolution and further re-growth of the longest crystals. The length of the crystals is now $20 \pm 5 \mu \mathrm{m}$. In each picture, the scale bar indicates $50 \mu \mathrm{m}$.

The micro-system that we developed, illustrated in Fig. 3, was aimed at performing statistics on crystallization events using a large number of identical conditions with the ultimate goal of extracting information on nucleation kinetics. The mAbs case studied here did not require the use of this design as the observations were identical in all droplets, but we will use this chip in the future to estimate nucleation kinetics for other proteins. Also note that the chip design can be easily adapted by adding multiple inlets and outlets in level $\mathrm{C}$, in order to simultaneously test different crystallization conditions on the same chip. For example, the design in Fig. 1 can be divided into two parallel rows of storage channels, each connected to independent inlets and outlets. Similarly, several water chemical activities can be simultaneously imposed on the chip by punching several 
open reservoirs in the PDMS layer of Level F. These modifications would be at the expense of the simplicity of use of the chip presented here, but should allow (moderate) screening of several crystallization conditions.

\section{Conclusions}

In the present work, we designed a simple twolevel PDMS chip which makes it possible to explore quantitatively the crystallization conditions of a protein solution in nanoliter droplets, as demonstrated on the case of a protein of interest: the monoclonal antibody anti-CD20. This original device mimics the classical hanging drop vapor diffusion method, but also offers several significant new opportunities. First, it is possible to change dynamically the imposed chemical activity $a_{w}^{i}$ by changing manually the solution in level $\mathrm{F}$ during an experiment. This makes it possible to tune dynamically the rate of volume change, and thus the rate of supersaturation change.

Also importantly, this microfluidic chip allows a quantitative knowledge of the droplets composition at any time $t$ simply by measuring their lengths. This is a unique feature as compared to the traditional hanging drop method to relate any events occurring in the drop (nucleation, phase separation, crystal dissolution) to the exact concentrations in solutes. Finally, the small scales of the channel ( $h=30 \mu \mathrm{m})$ ensures perfectly controlled mass transport conditions preventing for instance unwanted free convection for crystal growth that can occur in hanging drops. ${ }^{51}$

We see the need for a much more detailed understanding of phase diagrams and crystallization kinetics, which will lead to improved control over future production process in the pharmaceutical industry. We envisage that the possibilities offered by our disposable microfluidic chips that do not require any specific equipment or expertise, simplify the exploration of phase diagram and kinetics for such processes.

Acknowledgement The authors would like to thank J. Pullen for many fruitful discussions. We also thank Fujifilm Diosynth Biotechnolo- gies for providing anti-CD20 solutions. This research was funded by the European Union's Horizon 2020, Future and Emerging Technologies program (FET-OPEN), AMECRYS project (http://www.amecrys-project.eu/) under grant agreement no. 712965 .

\section{Supporting Information Avail- able}

The following files are available free of charge.

- Movie M1: This movie shows simultaneously three zooms on distinct areas of the channel during the experiment reported in Fig. 5.

\section{References}

(1) Hekmat, D. Large-scale crystallization of proteins for purification and formulation. Bioprocess and Biosystems Engineering 2015, 38, 1209.

(2) Stevens, R. C. High-throughput protein crystallization. Curr. Opin. Struct. Biol. 2000, 10, 558 .

(3) Hui, R.; Edwards, A. High-throughput protein crystallization. J. Struct. Biol. 2003, 142, 154.

(4) Luft, J. R.; Wolfley, J.; Jurisica, I.; Glasgow, J.; Fortier, S.; DeTitta, G. T. Macromolecular crystallization in a high throughput laboratory- the search phase. J. Crystal Growth 2001, 232, 591.

(5) Khurshid, S.; Govada, L.; Chayen, N. E. Dynamic screening experiments to maximize hits for crystallization. Cryst. Growth Des. 2007, 7, 2171-2175.

(6) Shi, H. H.; Xiao, Y.; Ferguson, S.; Huang, X.; Wang, N.; Hao, H. X. Progress of crystallization in microfluidic devices. Lab Chip 2017, 17, 2167-2185. 
(7) Zheng, B.; Gerdts, C. G.; Ismagilov, R. F. Using nanoliter plugs in microfluidics to facilitate and understand protein crystallization. Current Opinion in Structural Biology 2005, 15, 1.

(8) Hansen, C.; Quake, S. R. Microfluidics in structural biology: smaller, faster em leader better. Curr. Opin. Struct. Biol. 2003, 13, 538 .

(9) Leng, J.; Salmon, J.-B. Microfluidic crystallization. Lab Chip 2009, 9, 24.

(10) Sauter, C.; Dhouib, K.; Lorber, B. From Macrofluidics to Microfluidics for the Crystallization of Biological Macromolecules. Cryst. Growth Des. 2007, 7, 2247.

(11) Sui, S.; Perry, S. L. Microfluidics: From crystallization to serial time-resolved crystallography. Struct. Dyn. 2017, 4, 032202.

(12) Meldrum, F. C.; O'Shaughnessy, C. Crystallization in Confinement. Adv. Mater. 2020, 32, 2001068.

(13) Li, L.; Mustafi, D.; Fu, Q.; Tereshko, V.; Chen, D. L.; Tice, J. D.; Ismagilov, R. F. Nanoliter microfluidic hybrid method for simultaneous screening and optimization validated with crystallization of membrane proteins. Proc. Natl. Acad. Sci. USA 2006, 103, 19243.

(14) Hansen, C. L.; Sommer, M. O.; Quake, S. R. Systematic investigation of protein phase behavior with a microfluidic formulator. Proc. Natl. Acad. Sci U. S. A 2004, 101, 14431.

(15) Du, W.; Li, L.; Nichols, K. P.; Ismagilov, R. F. SlipChip. Lab Chip 2009, 9, 2286-2292.

(16) Zheng, B.; Roach, L. S.; Ismagilov, R. F. Screening of protein crystallization conditions on a microfluidic chip using nanoliter-size droplets. J. Am. Chem. Soc. 2003, 125, 11170.
(17) Khvostichenko, D. S.; Schieferstein, J. M.; Pawate, A. S.; Laible, P. D.; Kenis, P. J. A. X-ray transparent microfluidic chip for mesophase-based crystallization of membrane proteins and on-chip structure determination. Cryst. Growth Des. 2014, 14,4886 .

(18) Ildefonso, M.; Candoni, N.; Veesler, S. Using microfluidics for fast, accurate measurement of lysozyme nucleation kinetics. Cryst. Growth Des. 2011, 11, 1527.

(19) Selimović, S.; Jia, Y.; Fraden, S. Measuring the Nucleation Rate of Lysozyme using Microfluidics. Cryst. Growth Des. 2009, 9, 1806 .

(20) Akella, S. V.; Mowitz, A.; Heymann, M.; Fraden, S. Emulsion-Based Technique To Measure Protein Crystal Nucleation Rates of Lysozyme. Cryst. Growth Des. 2014, 14, 4487 .

(21) Pham, N.; Radajewski, D.; Round, A.; Brennich, M.; Pernot, P.; F., B. B.; Bonneté,; Teychené, S. Coupling High Throughput Microfluidics and SmallAngle X-ray Scattering to Study Protein Crystallization from Solution. Anal. Chem. 2017, 89, 2282-2287.

(22) Dolega, M. E.; Jakiela, S.; Razew, M.; Rakszewska, A.; Cybulski, O.; Garstecki, P. Iterative operations on microdroplets and continuous monitoring of processes within them; determination of solubility diagrams of proteins. Lab Chip 2012, 12, 4022.

(23) Anderson, M. J.; Hansen, C. L.; Quake, S. R. Phase knowledge enables rational screens for protein crystallization. Proc. Natl. Acad. Sci. USA 2006, 103, 16746.

(24) Hansen, C. L.; Skordalakes, E.; Berger, J. M.; Quake, S. R. A robust and scalable microfluidic metering method that allows protein crystal growth by free interface diffusion. Proc. Natl. Acad. Sci. USA 2002, 99, 16531. 
(25) Dhouib, K.; Malek, C. K.; Pfelging, W.; Gauthier-Manuel, B.; Duffait, R.; Thuillier, G.; Ferrigno, R.; Jacquamet, L.; Ohana, J.; Ferrer, J.-L.; TheobaldDietrich, A.; Giege, R.; Lorber, B.; Sauter, C. Microfluidic chips for the crystallization of biomacromolecules by counter-diffusion and on-chip crystal Xray analysis. Lab Chip 2009, 9, 1412.

(26) Perry, S. L.; Guha, S.; Pawate, A. S.; Bhaskarla, A.; Agarwal, V.; Nair, S. K.; Kenis, P. J. A. A Microfluidic Approach for Protein Structure Determination at Room Temperature via on-chip Anomalous Diffraction. Lab Chip 2013, 13, 31833187.

(27) Junius, N.; Jaho, S.; Sallaz-Damaz, Y.; Borel, F.; Salmon, J.-B.; BudayovaSpano, M. A microfluidic device for both on-chip dialysis protein crystallization and: In situ X-ray diffraction. Lab Chip 2020, 20, 296.

(28) Nguyen, H. T.; Massino, M.; Keita, C.; Salmon, J.-B. Microfluidic dialysis using photo-patterned hydrogel membranes in PDMS chips. Lab Chip 2020, 20, 2383.

(29) Deshpande, K.; Ahamed, T.; Van Der Wielen, L. A.; Ter Horst, J. H.; Jansens, P. J.; Ottens, M. Protein selfinteraction chromatography on a microchip. Lab Chip 2009, 9, 600.

(30) Hansen, C. L.; Classen, S.; Berger, J. M.; Quake, S. R. A microfluidic device for kinetic optimization of protein crystallization and in situ structure determination. J. Am. Chem. Soc. 2006, 128, 3142.

(31) Shim, J.; Cristobal, G.; Link, D. R.; Thorsen, T.; Fraden, S. Using Microfluidics to Decouple Nucleation and Growth of Protein Crystals. Cryst. Growth Des. 2007, 7, 2192.

(32) Luo, Y. H.; Li, G.; Chen, Q.; Zhao, J. L. Microfluidic device for automated highthroughput protein crystallization screening by osmotic dewatering. Chemical
Journal of Chinese Universities 2012, 33, 2178 .

(33) Ziane, N.; Guirardel, M.; Leng, J.; Salmon, J.-B. Drying with no Concentration Gradient in Large Microfluidic Droplets. Soft Matter 2015, 11, 36373642 .

(34) Yao, S.; Bethani, A.; Ziane, N.; Brochon, C.; Fleury, G.; Hadziioannou, G.; Poulin, P.; Salmon, J.-B.; Cloutet, E. Synthesis of a Conductive Copolymer and Phase Diagram of Its Suspension with Single-Walled Carbon Nanotubes by Microfluidic Technology. Macromolecules 2015, 48, 7473 .

(35) Nandy, L.; Dutcher, C. S. Phase Behavior of Ammonium Sulfate with Organic Acid Solutions in Aqueous Aerosol Mimics Using Microfluidic Traps. J. Phys. Chem. B 2018, 122, 3480.

(36) Bremer, A.; Mittag, T.; Heymann, M. Microfluidic characterization of macromolecular liquid-liquid phase separation. Lab Chip 2020, 20, 4225.

(37) Zhou, X.; Li, J.; Wu, C.; Zheng, B. Constructing the Phase Diagram of an Aqueous Solution of Poly(N-isopropyl acrylamide) by Controlled Microevaporation in a Nanoliter Microchamber. Macromol. Rapid Commun. 2008, 29, 1363.

(38) Casan, J.; Wong, J.; Northcott, M.; Opat, S. Anti-CD20 monoclonal antibodies: reviewing a revolution. Hum Vaccin Immunother 2018, 14, 2820.

(39) Unger, M. A.; Chou, H. P.; Thorsen, T.; Scherer, A.; Quake, S. R. Monolithic microfabricated valves and pumps by multilayer soft lithography. Science 2000, 288, 113.

(40) Ha, Z.; Chan, C. K. The Water Activities of $\mathrm{MgCl} 2, \mathrm{Mg}(\mathrm{NO} 3) 2, \mathrm{MgSO} 4$, and Their Mixtures. Aerosol Science and Technology 1999, 31, 154. 
(41) Han, H.; Li, D.; Guo, L.; Yao, Y.; Yang, H.; Zeng, D. Isopiestic measurements of water activity for the $\mathrm{NaCl}$ $\mathrm{KCl}-\mathrm{MgCl} 2-\mathrm{H} 2 \mathrm{O}$ systems at $323.15 \mathrm{~K}$. J. Chem. Eng. Data 2015, 60, 1139.

(42) Rard, J. A.; Miller, D. G. Isopiestic Determination of the Osmotic and Activity Coefficients of Aqueous $\mathrm{MgCl} 2$ Solutions at $25^{\circ} \mathrm{C}$. J. Chem. Eng. Data 1981, 26, 38 .

(43) Randall, G. C.; Doyle, P. S. Permeationdriven flow in poly(dimethylsiloxane) microfluidic devices. Proc. Natl. Acad. Sci. USA 2005, 102, 10813-10818.

(44) Noblin, X.; Mahadevan, L.; Coomaraswamy, I. A.; Weitz, D. A.; Holbrook, N. M.; Zwieniecki, M. A. Optimal vein density in artificial and real leaves. Proc. Natl. Acad. Sci. U. S. A 2008, 105, 9140-9144.

(45) Dollet, B.; Louf, J.-F.; Alonzo, M.; Jensen, K.; Marmottant, P. Drying of channels by evaporation through a permeable medium. J. R. Soc. Interface 2019, 16, 20180690 .

(46) Harley, S. J.; Glascoe, E. A.; Maxwell, R. S. Thermodynamic study on dynamic water vapor sorption in Sylgard-184. J. Phys. Chem. B 2012, 116, 14183-14190.

(47) Yang, M. X.; Shenoy, B.; Disttler, M.; Patel, R.; McGrath, M.; Pechenov, S.; Margolin, A. L. Crystalline monoclonal antibodies for subcutaneous delivery. Proc. Natl. Acad. Sci. USA 2003, 100, 6934.

(48) Yang, H.; Belviso, B. D.; Li, X.; Chen, W.; Mastropietro, T. F.; Di Profio, G.; Caliandro, R.; Heng, J. Optimization of vapor diffusion conditions for anti-CD20 crystallization and scale-up to meso batch. Crystals 2019, 9, 230.

(49) Pantuso, E.; Mastropietro, T. F.; Briuglia, M. L.; Gerard, C. J. J.; Curcio, E.; ter Horst, J. H.; Nicoletta, F. P.;
Di Profio, G. On the Aggregation and Nucleation Mechanism of the Monoclonal Antibody Anti-CD20 Near Liquid-Liquid Phase Separation (LLPS). Scientific Reports 8902, 10, 8902 .

(50) Guendouzi, M. E. L.; Mounir, A.; Dinane, A. Water activity, osmotic and activity coefficients of aqueous solutions of Li2SO4, Na2SO4, K2SO4, (NH4)2SO4, MgSO4, MnSO4, NiSO4, CuSO4, and $\mathrm{ZnSO} 4$ at $\mathrm{T}=298.15 \mathrm{~K}$. J. Chem. Thermodynamics 2003, 35, 209.

(51) Savino, R.; Monti, R. Buoyancy and surface-tension-driven convection in hanging-drop protein crystallizer. $J$. Crystal Growth 1996, 165, 308. 